\title{
HIV-Associated Oral Lesions in HIV-Seropositive Patients at an HIV- Treatment Clinic in South Africa
}

\section{Adeshnee Moodley and Neil Hamilton Wood*}

Department of Periodontology and Oral Medicine, School of Oral Health Sciences, Faculty of Health Sciences, Sefako Makgatho Health Sciences University, Pretoria, South Africa

\begin{abstract}
Introduction: Oral lesions may be the first indicator of HIV infection or of HIV-disease progression. Few studies have characterized oral lesions in HIV-seropositive South Africans receiving HAART. This aim of this study is to define the prevalence of HIV-associated oral lesions in a South African population sample and to investigate the relationship between these lesions and gender, age, CD4+ T-cell count, neutrophil count, viral load, type of HAART, and alcohol and tobacco use.
\end{abstract}

Methods: Four hundred and thirty five patients were interviewed and examined. Additional data was obtained from their hospital files. Descriptive statistics and Chi-squared tests with $p<0.05$ considered as significant, were applied.

Results: Four hundred and eighteen participants $(96 \%)$ were on HAART. Thirty-two $(7 \%)$ had oral lesions strongly associated with HIV infection and $24(6 \%)$ had 'other lesions'. Some presented with multiple lesions. A total of 41 oral lesions associated with HIV infection were recorded and of these, oral candidiasis was the most common (68\%). No relationships existed between the presence of oral lesions associated with HIV infection and gender, age, neutrophil count and alcohol and tobacco use.

Conclusions: The prevalence of oral lesions strongly associated with HIV-infection in this study population was significantly associated with CD4+ T cell count, viral load and the type of antiretroviral treatment.

Keywords: Oral lesions; Viral load; CD4; AIDS; HIV infection; HAART; Salvage treatment

Abbreviation: OLSAH: Oral Lesions Strongly Associated with HIV
Infection Infection

\section{Introduction}

The HIV/AIDS epidemic is firmly rooted in Sub-Saharan Africa with an estimated 22.5 million adults and children infected with HIV/AIDS. South Africa's epidemic is one of the largest globally with approximately 5.6 million infected people. The prevalence of HIV infection in African countries like Ethiopia, Nigeria, Zambia and Zimbabwe is also high with reported infection rates of up to $30 \%[1,2]$.

Globally, there is a slightly higher prevalence of HIV/AIDS infection amongst woman than men with more than $50 \%$ of all people infected with HIV being female, and in sub-Saharan Africa young women are at a much higher risk of being HIV positive than men [2]. This trend is noted in South Africa too, with more than half of the people in the country infected with HIV being female [3].

Oral lesions are often the first indicators of HIV infection or of disease progression to AIDS, and remain so in the era of highly active anti-retroviral therapy (HAART) [4-6]. Oral diseases associated with HIV infection negatively impact on the quality of life of infected patients and necessitate prompt diagnosis and treatment. The prevalence rates of oral diseases associated with HIV infection varies around the world and relates to the strain of HIV infection, to genetic factors and to the route of HIV transmission. Few studies have been done describing the prevalence of these oral lesions in Southern African populations infected with HIV and receiving HAART, and also, of the characteristics of these lesions [7-14].

Trends show a decrease in the prevalence in oral lesions in HIV-seropositive patients receiving HAART [5,15]. Unfortunately, developed countries and developing countries other than those in
Africa contributed the bulk of this literature. The applicability of the studies done in the developed global areas is of some, but not sufficient value to the Southern African rural and semi-rural populations and this study adds to the scant pool of data contributed from Sub-Saharan Africa.

This study describes the prevalence of HIV-associated oral lesions in HIV-seropositive patients receiving HAART at an HIV-management clinic in a semi-rural district of the Gauteng province in South Africa. It also describes the association between the presence of HIV-associated oral lesions in the study population and the parameters: gender, age, use of HAART, CD4+ T cell count, neutrophil count, viral load and tobacco and alcohol use.

\section{Materials and Methods}

HIV-seropositive patients attending an HIV-management clinic were sequentially recruited for this cross-sectional study. Based on a study of the available literature it was decided that all patients attending this clinic would be included in the study until the sample size was reached. A rounded sample size of 400 was determined using an

${ }^{*}$ Corresponding author: Neil $\mathrm{H}$ Wood, Head Clinical Unit, Oral Medicine and Periodontology, Department of Periodontology and Oral Medicine, School of Ora Health Sciences, Faculty of Health Sciences, Sefako Makgatho Health Sciences University, Pretoria, South Africa, Tel: 27125214834; E-mail: drnhwood@gmail.com; neil.wood@smu.co.za

Received December 05, 2014; Accepted January 19, 2015; Published January 26, 2015

Citation: Moodley A, Wood NH (2015) HIV-Associated Oral Lesions in HIV Seropositive Patients at an HIV-Treatment Clinic in South Africa. J AIDS Clin Res 6: 422. doi:10.4172/2155-6113.1000422

Copyright: ( $) 2015$ Moodley A, et al. This is an open-access article distributed unde the terms of the Creative Commons Attribution License, which permits unrestricted use, distribution, and reproduction in any medium, provided the original author and source are credited. 
Citation: Moodley A, Wood NH (2015) HIV-Associated Oral Lesions in HIV-Seropositive Patients at an HIV-Treatment Clinic in South Africa. J AIDS Clin Res 6: 422. doi:10.4172/2155-6113.1000422

Page 2 of 11

expected prevalence of $60 \%$ as determined in a previous study done in South Africa [7]. The sample size was calculated at 369 patients and a two-sided 95\% confidence interval for the true prevalence will extend $\pm 5 \%$ from the prevalence calculated from the sample and was based on the patient attendance at the clinic during the previous two years. A questionnaire-guided interview was completed with every patient and relevant data were extracted from the patients' records. The recorded information included age, gender, period of HIV-infection, CD4+ T-cell count, neutrophil count, viral load and anti-retroviral regimen.

Extra- and intra-oral examinations were performed by a calibrated clinician and the clinical findings were recorded on the data-collection sheet. The case definitions that were used for this study were those outlined by the Oral HIV/AIDS Research Alliance (OHARA) [16]. All oral lesions were provisionally diagnosed based on their clinical appearance using the OHARA case definitions, and were recorded and classified according to the European Community Clearinghouse (ECClearinghouse) diagnostic criteria [17]. For the purpose of this paper, the acronym OLSAH will be used to denote "oral lesions strongly associated with HIV infection". The different HAART regimens for adults and adolescents as used by this clinic at the time of data collection are shown in Appendix 1 [18].

Differences in the prevalence of HIV-associated oral lesions were compared between genders, different age groups, types of HAART, CD4+ T cell count, neutrophil count, viral load and the use of alcohol and smoking. All statistical procedures and tests were performed on SAS $^{\circ} 9.2$ software in Microsoft Windows, and were two-sided with p-values $\leq 0.05$ were considered significant.

Oral lesions commonly associated with HIV infection (Appendix

\begin{tabular}{|c|c|c|c|c|c|c|c|}
\hline \multirow{3}{*}{ Characteristics } & \multirow{3}{*}{ All Patients } & \multirow{3}{*}{ Percentage } & \multicolumn{3}{|c|}{ Patients with Oral Lesions } & \multirow{3}{*}{ Chi Square Test } & \multirow{3}{*}{ P-Value } \\
\hline & & & \multicolumn{2}{|c|}{ Current } & \multirow[t]{2}{*}{ Past } & & \\
\hline & & & Strongly & Other & & & \\
\hline \multicolumn{8}{|l|}{ Gender } \\
\hline Male & 134 & $30.8 \%$ & $12(8.96 \%)$ & 11 & 47 & \multirow{2}{*}{0.663} & \multirow{2}{*}{0.416} \\
\hline Female & 297 & $68.3 \%$ & $20(6.73 \%)$ & 13 & 128 & & \\
\hline Unknown & 4 & $0.9 \%$ & 0 & 0 & 2 & & \\
\hline \multicolumn{8}{|l|}{ Age } \\
\hline $13-19$ & 1 & $0.2 \%$ & $0(0 \%)$ & 0 & 0 & \multirow{6}{*}{2.264} & \multirow{6}{*}{0.812} \\
\hline $20-30$ & 81 & $18.6 \%$ & $4(4.94 \%)$ & 2 & 29 & & \\
\hline $31-40$ & 183 & $42.1 \%$ & $15(8.20 \%)$ & 11 & 79 & & \\
\hline $41-50$ & 119 & $27.4 \%$ & $8(6.72 \%)$ & 8 & 48 & & \\
\hline $51-60$ & 46 & $10.6 \%$ & $5(10.87 \%)$ & 3 & 18 & & \\
\hline $61-70$ & 5 & $1.1 \%$ & $0(0 \%)$ & 0 & 3 & & \\
\hline \multicolumn{8}{|l|}{ No. of years HIV+ } \\
\hline $0-7$ & 386 & $88.7 \%$ & $26(6.74 \%)$ & 21 & 151 & \multirow{3}{*}{2.368} & \multirow{3}{*}{0.306} \\
\hline 8-13 & 37 & $8.5 \%$ & $5(13.51 \%)$ & 1 & 21 & & \\
\hline $14-18$ & 10 & $2.3 \%$ & $1(10.0 \%)$ & 2 & 5 & & \\
\hline Unknown & 2 & $0.5 \%$ & 0 & 0 & 0 & & \\
\hline \multicolumn{8}{|l|}{ Smoker } \\
\hline Yes & 57 & $13.1 \%$ & $4(7.02 \%)$ & 5 & 25 & \multirow{2}{*}{0.012} & \multirow{2}{*}{0.912} \\
\hline No & 377 & $86.7 \%$ & $28(7.43 \%)$ & 19 & 152 & & \\
\hline Unknown & 1 & $0.2 \%$ & 0 & 0 & 0 & & \\
\hline \multicolumn{8}{|l|}{$\begin{array}{l}\text { Alcohol } \\
\text { Consumption }\end{array}$} \\
\hline Yes & 63 & $14.5 \%$ & $4(6.35 \%)$ & 6 & 33 & \multirow{2}{*}{0.133} & 0737 \\
\hline No & 371 & $85.3 \%$ & $28(7.55 \%)$ & 18 & 144 & & 0.131 \\
\hline Unknown & 1 & $0.2 \%$ & 0 & 0 & 0 & & \\
\hline Antiretroviral Tx & & & & & & & \\
\hline Type 1 & 341 & $78.4 \%$ & $19(5.57 \%)$ & 17 & 126 & & \\
\hline Type2 & 17 & $3.9 \%$ & $1(5.88 \%)$ & 2 & 6 & 21732 & $<0001$ \\
\hline Salvage & 60 & $13.8 \%$ & $6(10.00 \%)$ & 2 & 35 & 21.132 & $<0.001$ \\
\hline Not started & 17 & $3.9 \%$ & $6(35.29 \%)$ & 3 & 10 & & \\
\hline CD4 cell count & & & & & & & \\
\hline$<200$ & 179 & $41.1 \%$ & $23(12.85 \%)$ & 12 & 78 & & \\
\hline $200-500$ & 175 & $40.2 \%$ & $6(3.43 \%)$ & 7 & 68 & 13.868 & 0.001 \\
\hline$>500$ & 50 & $11.5 \%$ & $1(2.00 \%)$ & 2 & 16 & & \\
\hline Unknown & 31 & $7.1 \%$ & 2 & 3 & 15 & & \\
\hline Neutrophil Coun & & & & & & & \\
\hline$<2$ & 160 & $36.8 \%$ & $13(8.13 \%)$ & 9 & 66 & & 0536 \\
\hline$\geq 2$ & 246 & $56.6 \%$ & $16(6.50 \%)$ & 13 & 96 & 0.384 & 0.536 \\
\hline Unknown & 29 & $6.7 \%$ & 3 & 2 & 15 & & \\
\hline Viral Load & & & & & & & \\
\hline$<40$ & 119 & $27.4 \%$ & $2(1.7 \%)$ & 4 & 41 & & \\
\hline $40-10000$ & 130 & $29.9 \%$ & $5(3.8 \%)$ & 4 & 56 & 23.146 & $<0.001$ \\
\hline$>10000$ & 71 & $16.3 \%$ & $13(18.3 \%)$ & 6 & 29 & & \\
\hline Unknown & 0 & $0.0 \%$ & 12 & 10 & 51 & & \\
\hline
\end{tabular}

Table 1: Data Summary. 
2) were recorded on the data collection sheet and those patients who presented with any oral lesions were referred to the Department of Periodontology and Oral Medicine for further management. All records remained confidential and all of the referred patients' treatment needs were addressed. Ethical clearance was obtained prior to the commencement of data-collection.

\section{Results}

The results of this study are summarized in Table 1. A total of 435 patients participated in this study. One hundred and thirty-four (30.8\%) were males, 297 (68.35\%) were females and 4 patients' genders were not recorded (Table 1). The study population age range was between 13-70 years. There were 32 patients who presented with OLSAH at the time of examination. Some patients presented with more than one lesion upon examination. Therefore, a total of 41 OLSAH were recorded (Table 2). Lesions that did not fall into the category of being strongly associated with HIV infection were grouped as 'other lesions'. In total 24 patients with 'other lesions' were recorded.

Study participants' ages were stratified into the intervals 13-19, 20 $30,31-40,41-50,51-60$ and $61-70$ years. The majority of the patients who presented with oral lesions fell into the age categories of 31-40 and 41-50. The age group of 31-40 years had 15 (49.6\%) participants who presented with OLSAH and 11 (45.8\%) presented with 'other lesions'.

The period of HIV-seropositivity for each patient was recorded and categorised into 3 groups: those diagnosed between 0-7 years ago, between 8-13 years ago and between $14-18$ years ago. These figures are arbitrary. Two participants $(0.5 \%)$ were unable to recall when they were diagnosed with HIV infection but did not present with any oral lesions.

\begin{tabular}{|c|c|c|c|c|}
\hline & $\mathbf{N}$ & $\%$ & HAART & Non-HAART \\
\hline \multicolumn{5}{|l|}{ Oral Lesions } \\
\hline Strongly Associated & 41 & $100 \%$ & & \\
\hline Oral Candidiasis & 28 & $68.3 \%$ & 21 & 7 \\
\hline -Pseudomembranous & 13 & $31.7 \%$ & & \\
\hline -Erythematous & 5 & $12.2 \%$ & & \\
\hline -Angular Cheilitis & 10 & $24.4 \%$ & & \\
\hline Hairy Leukoplakia & 5 & $12.2 \%$ & 5 & 0 \\
\hline Kaposi Sarcoma & 0 & $0.0 \%$ & 0 & 0 \\
\hline Non Hodgkin Lymphoma & 0 & $0.0 \%$ & $\mathbf{0}$ & 0 \\
\hline Gingival Lesions & 3 & $7.3 \%$ & 3 & 0 \\
\hline - Linear Gingival Erythema & 1 & $2.4 \%$ & 1 & 0 \\
\hline - Necrotizing Gingivitis & 2 & $4.9 \%$ & 2 & 2 \\
\hline - Necrotizing Periodontitis & 0 & $0.0 \%$ & 0 & 0 \\
\hline Ulcers & 5 & $12.2 \%$ & 4 & 1 \\
\hline -Aphthous & 5 & $12.2 \%$ & 4 & 1 \\
\hline - Not otherwise specified & 0 & 0 & 0 & 0 \\
\hline Other Oral Lesions & $\underline{26}$ & & & \\
\hline Candidiasis* $^{*}$ & 4 & $15 \%$ & & \\
\hline Herpes Labialis & 4 & $15 \%$ & & \\
\hline Oral Warts & 2 & $8 \%$ & & \\
\hline Lymphoma & 1 & $4 \%$ & & \\
\hline Hyperpigmentation & 1 & $4 \%$ & & \\
\hline Parotid Gland Swelling & 1 & $4 \%$ & & \\
\hline Non Specific lesion & 13 & $54 \%$ & & \\
\hline
\end{tabular}

* 3 cases of median rhomboid glossitis and 1 case of oropharyngeal candidiasis Table 2: Distribution of oral lesions in 56 study participants. Multiple oral lesions were found in some participants.
Three hundred and eighty six (88.7\%) participants were diagnosed with HIV infection between 0-7 years ago, 37 (8.5\%) participants were diagnosed with HIV infection between 8-13 years ago and $10(2.3 \%)$ were diagnosed with HIV infection between 14-18 years ago. This is to our knowledge the only study to report this variable despite its limitations.

Twenty six (81.3\%) patients with OLSAH were diagnosed with HIV infection between 0-7 years ago. Five (15.6\%) patients with OLSAH were diagnosed with HIV infection between 8-13 years ago and only $1(3.1 \%)$ patient with an OLSAH was diagnosed with HIV infection between $14-18$ years ago. Twenty one (87.5\%) patients with 'other lesions' fell into the category of patients being diagnosed with HIV infection between $0-7$ years ago, 1 (4.2\%) patient in the category between $8-13$ years ago and $2(8.3 \%)$ patients in the category between 14-18 years ago.

Of the 435 participants, 57 (13.1\%) were smokers and 377 (86.7\%) were non-smokers. The information regarding the smoking status of one patient was not recorded. In the smoking group 4 (12.5\%) patients presented with OLSAH and $5(20.8 \%)$ with 'other lesions'. In the nonsmoking group 28 (87.5\%) patients had OLSAH and 19 (79.2\%) patients had 'other lesions'. These oral lesions were not induced by smoking.

Sixty three (14.5\%) patients in our sample group consumed alcohol and $371(85.3 \%)$ did not. Of those who consumed alcohol, $5(12.5 \%)$ had OLSAH and $6(25 \%)$ had 'other lesions'. In the group of participants who did not consume alcohol, 28 (87.5\%) patients had OLSAH and 18 (75\%) patients had 'other lesions'.

Thirty two (79\%) of the 41 OLSAH were seen in participants who did not consume alcohol or smoke. Participants who only consumed alcohol and did not smoke presented with 5 (12\%) OLSAH. Three (7\%) OLSAH were seen in participants who only smoked and did not consume alcohol, and only 1 (2\%) OLSAH was found in the group of patients who consumed alcohol and smoked.

Participants were also categorised into those receiving HAART type 1, type 2 and salvage therapy. Also, a group of participants who had not started treatment at the time of data collection was seen. Three hundred and forty one (78.4\%) participants were on HAART type 1, 17 (3.9\%) were on HAART type 2 and 60 (13.8\%) were on Salvage therapy. Seventeen $(3.9 \%)$ were still in the pre-treatment counselling phase and had not started HAART at the time. Of the patients on HAART type 1, 19 (59\%) presented with OLSAH and 17 (70.8\%) had 'other lesions'. The HAART type 2 group had 1 (3\%) patient with OLSAH and 2 (8.3\%) with 'other lesions'. Six (19\%) patients on salvage treatment presented with OLSAH and $2(8.3 \%)$ patients had 'other lesions'. Of the patients who had not started treatment at the time $6(19 \%)$ with OLSAH and 3 (12.5\%) with 'other lesions' were observed.

Participants were divided into 3 groups based on the latest CD4+ T cell count. Of the 435 participants, 179 (41.1\%) had a CD4+ T cell count lower than 200, 175 (40.2\%) had a CD4+ T cell count between 200-500 and $50(11.5 \%)$ had a CD4+ T cell count above 500 . Thirty one patients' (7.1\%) CD4+ T cell counts were not available.

In the group of patients who had CD4+ T cell counts lower 200 cells $/ \mathrm{mm}^{3}, 23(71.9 \%)$ presented with OLSAH and 12 (50\%) with 'other lesions'. In the group of participants who had CD4+ T cell counts between $200-500$ cells $/ \mathrm{mm}^{3}$, $6(18.8 \%)$ presented with OLSAH and 7 (29.2\%) with 'other lesions'. In the group of patients who had CD4+ T cell counts above 500 cells $/ \mathrm{mm}^{3}, 1(3.1 \%)$ presented with OLSAH and $3(12.5 \%)$ with 'other lesions'. In the group of patients with unknown 
CD4+ T cell counts, $2(6.3 \%)$ presented with OLSAH and $3(12.5 \%)$ with 'other lesions'.

Participants were divided into 2 groups according to their neutrophil count. One hundred and sixty (36.8\%) participants had neutrophil counts of less than $2 \times 10^{9} / \mathrm{L}$ and $246(56.6 \%)$ participants had neutrophil counts equal to or greater than $2 \times 10^{9} / \mathrm{L}$. Twenty nine (6.7\%) participants' neutrophil counts were unknown. In the group of participants with low neutrophil counts, $13(8.13 \%)$ had OLSAH and $9(5.62 \%)$ had 'other lesions'. In the group of patients with a neutrophil count equal to or greater than $2 \times 10^{9} / \mathrm{L}, 16(6.50 \%)$ had OLSAH and $13(5.28 \%)$ had 'other lesions'. In the group of patients whose neutrophil counts were unknown, $3(10.3 \%)$ had OLSAH and $2(6.9 \%)$ had 'other lesions.

All participants with viral load values were categorised into 3 groups according to their viral loads: $<40,40-10000$ and $>10000$ RNA cps/ml. There were 115 (26.4\%) patients who did not have viral load values at the time of examination. One hundred and nineteen (27.4\%) participants had viral loads less than 40 RNA cps/ml, $130(29.9 \%)$ had viral loads between 40- 10000 RNA cps/ml and 71 (16.3\%) had viral loads greater than $10000 \mathrm{RNA}$ cps/ml. Of the 119 patients who had viral loads $<40$ RNA cps/ml, 2 (1.7\%) had OLSAH and $4(3.4 \%)$ presented with 'other lesions'. In the group of participants having viral loads between $40-10000$ RNA cps/ml, 5 (3.8\%) presented with OLSAH and $4(3.1 \%)$ had 'other lesions. Thirteen patients with OLSAH and 6 (8.5\%) with 'other lesions' were noted in the group of patient with viral loads over $10000 \mathrm{RNA} \mathrm{cps} / \mathrm{ml}$.

Forty one lesions strongly associated with HIV infection were observed in this study (Table 2). Of the 41 lesions, pseudomembranous candidiasis was the most prevalent, with 13 (31.7\%) lesions; angular cheilitis was the second most prevalent lesion with 10 (24.4\%) lesions. Five (12.2\%) observations each of hairy leukoplakia, ulcers and erythematous candidiasis where recorded. Necrotizing gingivitis was observed twice (4.9\%) and linear gingival erythema was observed once (2.4\%).

Eighty percent of the OLSAH infections were observed in participants who were already on HAART. Twenty one (75\%) of the oral candidiasis lesions were seen in participants on HAART and 7 (25\%) were seen in participants who were not on HAART. All 5 (100\%) hairy leukoplakia lesions and all $3(100 \%)$ gingival lesions seen were observed in participants on HAART. There were 5 ulcers seen, 4 (80\%) were in participants on HAART and $1(20 \%)$ was seen in a patient who was not on HAART.

\section{Study limitations}

As with similar studies in this field limitations may include the unreliable and inaccurate recollection of patients regarding their history of opportunistic infections or oral lesions. In addition the period of HIV-seropositivity is not an accurate reflection as many of these patients wait very long before being tested resulting in a skewed figure of period of HIV seropositivity.

Lost files and patients who transferred from other clinics or hospitals without copies of their blood results from the referring source resulted in missing frequencies for 31 patients' CD $4+\mathrm{T}$ cell counts, of 29 patients' neutrophil counts and 115 patients' viral loads.

\section{Discussion and Literature Review}

Due to the high reported prevalence rate of HIV-associated oral lesions, more than half of the participants in some studies presented with oral lesions [19-21], but this was not the case in this study where only $7 \%$ presented with OLSAH and $6 \%$ with 'other' oral lesions. It is also frequently noted that patients may present with more than one HIV-associated oral lesion at the same point in time as was the case in our study. In addition, patients may present with OLSAH concurrently with 'other' oral lesions [20,22-24].

Fungal, bacterial and viral infections together with neoplasms, idiopathic conditions, salivary gland diseases and ulcers (not otherwise specified) contribute to the group of lesions that are associated with HIV infection [16]. These HIV-associated oral lesions not only play an important part in the assessment of HIV-disease progression [1], but also may be the first indicator that a patient may be infected with HIV.

A patient's treatment is regarded as failed or failing when a sustained or notable rise in viral loads and/or fall in CD4+ T cell count are seen [25]. Ideally the goal of HAART is to achieve viral loads that are lower than detectable limits. Blips, which are transient raises in viral load, do occur, especially when a patient is not well or has recently been vaccinated. This transient raise does not indicate failure, and further blood tests should be carried out to confirm or dismiss suspicions of failure. Failure can be due to several factors including the development of resistance to the drug and non-adherence to the medication [25].

\section{Clinical diagnostic criteria}

The EC-Clearinghouse [17] clinical diagnostic criteria separates HIV-associated oral lesions into 3 groups, and has been the term of reference for several studies dealing with HIV-associated oral diseases $[1,3,16,19,22,26,27]$.

The existing clinical diagnostic criteria for the conditions contained in the EC Clearinghouse paper were revised by the Oral HIV/AIDS Research Alliance (OHARA) to be applied in epidemiologic studies dealing with oral lesions in HIV-infected individuals [16]. The revised criteria are classed into 6 headings which contain the case definitions for the conditions listed there under. Contained within the original EC Clearinghouse criteria [17] as 'melanotic hyperpigmentation', but not included in the OHARA revised criteria [16], was the heading of 'mucosal hyperpigmentation' as described by Hamza et al. [15]. Similarly, 'linear gingival erythema' has been included under the heading of 'bacterial infection' for the purposes of this project (Appendix 1) [5,28]. Therefore, this paper is also unique in its reporting of the oral lesions according to the above descriptors and criteria for resource-poor settings and could serve as a guide for future study designs.

\section{Prevalence and incidence of HIV-associated oral lesions}

Previous studies showed that the prevalence of oral lesions in AIDS patients could be as high as $90 \%$ [23]. However, in these studies none of the participants were receiving anti-retroviral treatment whereas a studies done on patients receiving HAART showed prevalence could be as high as $53.24 \%$ [23] and in HIV-seropositive children on HAART it ranged between $15 \%$ and $63 \%[8,13,29]$ and still, despite antiretroviral therapy being administered, oral lesions still occur in some patients [30], also clearly seen in this study.

Some HIV-associated oral diseases tend to be more prevalent in some countries than others. Oral hairy leukoplakia and Kaposi sarcoma (KS) show the most variation in prevalence when comparing Western to Eastern countries. Oral hairy leukoplakia and KS have a lower prevalence in Asia [22] and this difference was speculated to relate to the higher incidence of men having sex with men in the western world $[22,24]$. 
Different trends in the prevalence of different HIV-associated oral lesions also exist amongst people from different socio-economic groups and people with different levels of education. Patients from lower socio-economic backgrounds present with higher levels of pseudomembranous candidiasis whereas those from higher socioeconomic backgrounds present with higher levels of salivary gland disease. HIV sero-positive individuals who had lower levels of education also present with poor oral care [31]. We considered our study population to be from an impoverished background with lower levels of education which supports the above in that only one case of salivary gland pathology was seen.

Several studies carried out in different countries showed candidiasis as the most prevalent lesion both in HIV positive patients on HAART and in HAART-naïve patients. Pseudomembranous candidiasis is also the most prevalent of the candidal infections. It has also been noted that the prevalence of candidiasis is higher in developing countries $[1,4]$. This proved to be true in many studies in Africa and South Africa $[4,30]$, including in this study.

The prevalence of OHL varies in different regions having a prevalence rate of 0.42 to $38 \%$ [1]. There is definitely a higher prevalence in the European countries as compared to Africa with the 2 studies showing very low prevalence rates $[4,15]$. In Africa, KS prevalence rates range between $0-12 \%$ and in developed worlds (USA and Europe) it ranges between $0-38 \%$ [1]. No cases of oral KS were found in this study population and 5 cases of OHL were recorded.

Common oral bacterial infections seen in HIV-seropositive patients include linear gingival erythema and the necrotizing periodontal diseases necrotizing gingivitis (NG) and necrotizing periodontitis NP. Prevalence rates range between $11-25 \%$ for NG, $1-18 \%$ for NP and 9-50\% for linear gingival erythema [32,33]. Likewise, these infection rates also differ from region to region. In other African studies the prevalence rates also vary from $2.4-11 \%[4,15]$.

\section{The effect of HAART on HIV-associated oral lesions}

Since the introduction of anti-retroviral treatment and HAART, HIV infected patients have had a better prognosis and a better life expectancy as a result of the reduction of viral replication and an increase in CD4+ $\mathrm{T}$ cell count [23]. This in turn meant that more patients would seek treatment for their HIV-associated oral lesions than in the past $[26,34]$. Although one may argue that because of a restored immune system, less oral manifestations should occur, this doesn't imply total eradication of HIV-associated oral lesions in patients on HAART. Healthcare workers should therefore be well equipped to deal with such lesions, as these lesions often negatively affect the quality of life of patients if left untreated $[10,35,36]$.

Studies done on patients on HAART indicate specific trends regarding HIV-associated oral lesions. There is an overall decrease in prevalence of HIV-associated oral lesions in HIV-seropositive patients on HAART compared to HAART-naïve HIV-seropositive patients, which has been significant and dropped from $47 \%-85 \%$ to $32 \%-46 \%$ $[5,30,37]$. The prevalence of oral candidiasis, oral hairy leukoplakia, Kaposi sarcoma, and oral herpes simplex infection is significantly decreased in HIV-seropositive patients on HAART. However, the frequency of Human Papillomavirus (HPV) -induced diseases has increased by 6 fold in some studies, and salivary gland diseases are also more prevalent in patients on with HAART compared to HAART-naïve HIV-seropositive persons [4,16,27].

At the time of data collection, HAART initiation followed South
African national guidelines and patients who were eligible to start treatment either have CD4+ T cell counts below 200 cells $/ \mathrm{mm}^{3}$, or patients classified as WHO stage IV at any CD4+ T cell count or in patients who present with MDR/XDR tuberculosis at any CD4+ T cell count [18].

We noted that most of our study participants (88.7\%) were diagnosed as being HIV-seropositive in the last 7 years. This was the result of all newly diagnosed HIV seropositive patients from the region being referred to this clinic for counselling and treatment initiation. Only once their condition had been controlled were they referred back to satellite clinics which are closer to their homes. The time at which the patient is diagnosed with HIV therefore differs from the time of infection, which would account for the differences seen in patients being diagnosed at the same point in time as they have most probably acquired their HIV infection at different times.

In 2006, Ranganathan and Hemalatha conducted an overview of studies done on oral lesions in HIV infection in developing countries. They noted the importance of these oral lesions as markers in disease progression. The study also commented on the regional distribution of certain lesions and stressed the need for studies on HIV-associated oral lesions to be conducted in the developing world. The article analysed studies on HIV associated oral lesions from developing countries from 1990-2004. In total, 44 articles were reviewed from Thailand, India, Africa and Latin America [29].

Oral candidiasis was the most prevalent lesion and the pseudomembranous type is the most common variant. Oral hairy leukoplakia was one of the lesions that exhibited a variable regional distribution, with the prevalence as high as $43 \%$ in some regions and as low as $7 \%$ in others. The prevalence aphthous ulcers and oral hyperpigmentation and oral KS also varied in different regions. The difference in the oral KS prevalence is also due to the HHV-8 which is endemic to certain regions. Salivary gland diseases were only reported in studies from Africa and Thailand. Periodontal disease also varied in different regions but was most prevalent in Africa and India, which was also attributed to poor nutrition and poor oral hygiene [29].

HIV-associated oral KS was not observed in this study, even in patients that were HAART-naïve. In the portion of patients receiving HAART, the absence of KS could be attributed to the positive response KS has shown to HAART. However, in the HAART-naïve group one can possibly attribute the absence of KS to the random recruitment used when including participants into the study.

Of the oral lesions seen in this study, candidiasis proved to be the most prevalent, making up $41.8 \%$ of all oral lesions recorded and pseudomembranous candidiasis was the most prevalent type of candidal infection noted. As seen in appendix 3, a high occurrence rate of pseudomembranous candidiasis was seen some studies $[7,19,28]$. In other similar studies, erythematous candidiasis was the most prevalent of the candidal infections $[27,38]$.

The prevalence of necrotizing periodontal disease in this study was much lower than compared to a similar study [39], having a prevalence rate of only $3 \%$ (Appendix 3).

Oral hairy leukoplakia had a prevalence of $7.5 \%$ in this study which is similar to the results obtained from the study done by Bodhade et al. [38]. The low prevalence noted may be attributed to the regional trends noted in some studies [1]. Linear gingival erythema had a low prevalence in this study and one done by Taiwo and Hassan [27], being $1.5 \%$ and $1 \%$ respectively. 
Oral hyperpigmentation may be attributed to the drugs HIVseropositive patients were taking. This could account for the high prevalence of mucosal hyperpigmentation in some studies $[19,27]$ but does not explain the high prevalence noted in the study done by Bodhade [38], where oral hyperpigmentation prevalence was $16 \%$.

Six percent of all oral lesions in this study were attributed to herpes simplex infections, this figure is higher when compared to 3 similar studies where herpes simplex infections were recorded (Appendix 3).

One patient $(1.5 \%)$ presented with salivary gland enlargement. This is comparable to other studies even though HIV-seropositive patients may present with salivary gland enlargement early on and after initiation of HAART. It is also known that HIV-seropositive patients on HAART have a higher prevalence of salivary gland enlargement than HIV-seropositive patients not on ART or HAART [1,23], but this difference is not seen when a comparison with other studies is made.

Human papillomavirus (HPV) infection is another condition that has been seen to increase after initiation of HAART. The prevalence of HPV infection in this study however, was very low (3\%). This result is comparable to the study done by Patton [28], where majority of the participants were also on ARV's, but from a developed country.

There were $5(7.5 \%)$ aphthous ulcers seen in the 67 oral lesions that were recorded. This value was similar to that seen in the study done by Taiwo and Hassan [27]. With regards to ulcers, many studies did not differentiate between ulcers not otherwise specified and recurrent aphthous ulceration. This made it difficult to accurately compare these lesions (Appendix 3).

Since 2006, many studies contributed to the 44 papers reviewed by Ranganathan and Hemalatha [29]. Appendix 4 contains some of the more recent studies from developing countries, but is by no means a systematic review.

Some problems encountered when comparing and contrasting these studies were that some articles report the prevalence of oral lesions as a percentage of the sample size, while others report it as a percentage of the total number of lesions. Some articles also do not specify the subtype of lesions been reported, for example the type of oral candidiasis being recorded, or the type of oral ulcerations present which made the comparisons of the lesions between studies impossible. In addition, many studies did not follow a standardized protocol of lesion diagnosis which makes it nearly impossible to compare data across studies.

Some reasons for the variations in reports by different studies include differences in study design and nature, in the route of HIV transmission and in the initiation of ART or HAART regarding timing and dosage among other variables.

The difference in prevalence of OLSAH and 'other lesions' between men and women was not significant $(\mathrm{p}=0.416)$. One hundred and eighty three patients (42.1\%) fell into the 31-40 age category, and 15 (46.9\%) patients presenting with OLSAH infection fell into this age category (Appendix 1). Although there was a difference in prevalence of OLSAH and 'other lesions' between the age groups, this difference was not significant $(\mathrm{p}=0.812)$.

The even distribution of OLSAH re-enforces the idea that HIVseropositive individuals may develop oral lesions at any stage of HIVinfection [33], and the prevalence of oral lesions in HIV-seropositive patients receiving HAART is significantly lower than those not on HAART $[5,27,45]$.
No difference was found in the prevalence of OLSAH and "other lesions" between the 3 categories for the number of years of HIV infection. Therefore no significant increase or decrease was seen in the prevalence of OLSAH infection or "other lesions" as the period of HIVseropositivity progressed (Table 1).

Smoking and alcohol use did not significantly affect the prevalence of OLSAH infection or 'other lesions' in the participants. It was interesting to the note that just over $80 \%$ of the participants did not smoke or consume alcohol and $32(78 \%)$ OLSAH infection was found in this group of participants. Patients are given advice during the pretreatment counselling sessions on how to make better life style choices, this could account or the large number of non-smokers and patients who did not consume alcohol.

Palacio et al. [46] showed that HIV-seropositive smokers are at a higher risk for developing oral candidiasis and oral warts but are a less likely to develop oral ulcers, but Nittayananta et al. [47] showed no association between smoking and the prevalence of HIV associated oral lesions as in our study. Alcohol consumption was proven to be a significant factor in determining the prevalence of oral lesion in HIV positive patients [47] but in our study of predominantly HAARTpatients this could not be established. It is also important to note that even in HIV-seronegative patients, those who consume alcohol are at a higher risk of developing oral mucosal lesions [48].

In total, $56(12.9 \%)$ participants presented with oral lesions, 32 with OLSAH infection and 24 with 'other lesions'. This is similar to the results obtained by Bhayat et al., in 2008 (Appendix 3) [39]. This low prevalence could be attributed to the fact that majority of our participants $(96.1 \%)$ were already on HAART at the time of the study $[5,27,45]$. It is notable that in a study in which all participants received HAART, the prevalence of HIV associated oral lesions was at $47 \%$ [27]. In our study, a total of 67 lesions were recorded in these 56 patients, as some patients presented with more than one oral lesion (Table 2).

The line of HAART was a significant factor in determining the prevalence of OLSAH $(\mathrm{p}<0.001$; chi-square test $)$. The few patients, who had not started treatment, and those on salvage treatments, had a significantly higher risk of developing OLSAH. Patients on HAART have a lower prevalence of OLSAH compared to those not on any treatment, as patients who have not initiated treatment often have low $\mathrm{CD}+\mathrm{T}$ cell counts, and are therefore prone to more opportunistic infections [2]. Patients were only placed on salvage treatment if they experienced treatment failure using either of the $2^{\text {nd }}$ line HAART regimens. Treatment failure implies that the patient had a sustained or an increased viral load or decreased CD4+ T cell count [25]. This may also render a patient more susceptible to opportunistic infections and therefore correlates to this group of patients having a significantly higher risk of developing OLSAH. This will also aid in patient management, as patients on treatment, who present with these lesions, may be experiencing treatment failure or are not compliant with taking their medication. In the latter case, the patients are said to have 'defaulted'. This significant correlation between viral load and CD4+ T cell count and the presence of OLSAH should warrant immediate investigation if the patient presents with OLSAH whilst on HAART.

The CD4+ $\mathrm{T}$ cell count proved to be a significant factor in determining the prevalence of OLSAH. Patients with CD4+ T cell counts $<200$ had a significantly higher risk of developing OLSAH as compared to patients with higher CD4+ $\mathrm{T}$ cell values [35]. The lower CD4+ T cell count renders the patient more prone to opportunistic infections and therefore correlates to the increase in OLSAH seen in this group of patients. 
The neutrophil count was not a significant factor in determining the prevalence of OLSAH even though patients with a neutrophil count less than $2 \times 10^{9} / \mathrm{L}$ presented with a higher percentage of OLSAH.

Together with the antiretroviral treatment and the $\mathrm{CD}+\mathrm{T}$ cell count, the viral load was also a significant factor in determining the prevalence of OLSAH for the study participants. The results of this study showed that patients with viral load values $>10000$ had a significantly higher prevalence of OLSAH (chi square test, $p$-value $\leq 0.001$ ). This had clinical significance since the occurrence of OLSAH in patients on HAART may indicate high viral loads; hence, the presence of oral lesions could imply treatment failure as mentioned earlier. However, whether or not OLSAH were related to HIV-disease progression, to side effects resultant from HAART, or to non-adherence to treatment cannot be elucidated from this study's data.

Of the oral lesions seen in this study, candidiasis proved to be the most prevalent, making up $31.7 \%$ of all OLSAH. The prevalence of necrotizing periodontal disease in this study was much lower than compared to similar studies [39], having a prevalence rate of only $3 \%$ (see Appendix 3). Oral hairy leukoplakia had a prevalence of $7.5 \%$ which is similar to the results obtained from the study done by Bodhade et al. [38]. One case of linear gingival erythema was noted in a patient receiving HAART.

\section{Report of multivariate analyses}

Several variables from Table 1 where further analysed to confirm the significant interactions between variables and prevalence of OLSAH. Viral loads have already shown to have a significant predictive value when assessing OLSAH. This relationship is even stronger in nonsmokers, as seen in Table 3. The same is seen in smokers.

When viral loads and CD 4+ T-cell counts were assessed, CD

\begin{tabular}{|c|c|c|c|c|c|c|}
\hline Viral Load - Non-Smoker & All Patients & $\%$ & \multicolumn{2}{|c|}{ OLSAH } & Chi Square Test & P-Value \\
\hline$<40$ & 137 & $36.3 \%$ & $2.2 \%$ & 3 & \multirow{4}{*}{17.2374} & \multirow{4}{*}{0.0006} \\
\hline $40-10000$ & 76 & $20.2 \%$ & $3.9 \%$ & 3 & & \\
\hline$>10000$ & 65 & $17.2 \%$ & $16.9 \%$ & 11 & & \\
\hline unknown & 99 & $26.3 \%$ & $11.1 \%$ & 11 & & \\
\hline Viral Load - Smoker & All Patients & $\%$ & \multicolumn{2}{|c|}{ OLSAH } & Chi Square Test & P-Value \\
\hline$<40$ & 20 & $35.1 \%$ & $0.0 \%$ & 0 & \multirow{4}{*}{7.7561} & \multirow{4}{*}{0.0478} \\
\hline $40-10000$ & 15 & $40.5 \%$ & $6.7 \%$ & 1 & & \\
\hline$>10000$ & 6 & $27.3 \%$ & $33.3 \%$ & 2 & & \\
\hline unknown & 16 & $33.3 \%$ & $6.3 \%$ & 1 & & \\
\hline Viral Load - CD4 cell count $(<200)$ & All Patients & $\%$ & \multicolumn{2}{|c|}{ OLSAH } & Chi Square Test & P-Value \\
\hline $40-10000$ & 32 & $18.1 \%$ & $6.1 \%$ & 2 & \multirow{4}{*}{13.1065} & \multirow{4}{*}{0.0038} \\
\hline$<40$ & 33 & $18.6 \%$ & $0.0 \%$ & - & & \\
\hline unknown & 66 & $37.3 \%$ & $26.1 \%$ & 17 & & \\
\hline$>10000$ & 46 & $26.0 \%$ & $13.6 \%$ & 6 & & \\
\hline Viral Load - CD4 cell count(200 - 500) & All Patients & $\%$ & \multicolumn{2}{|c|}{ OLSAH } & Chi Square Test & P-Value \\
\hline $40-10000$ & 47 & $26.6 \%$ & $4.3 \%$ & 2 & \multirow{4}{*}{0.5377} & \multirow{4}{*}{0.9401} \\
\hline$<40$ & 85 & $48.0 \%$ & $2.4 \%$ & 2 & & \\
\hline unknown & 23 & $13.0 \%$ & $4.5 \%$ & 1 & & \\
\hline$>10000$ & 22 & $12.4 \%$ & $4.3 \%$ & 1 & & \\
\hline Viral Load - CD4 cell count(> 500) & All Patients & $\%$ & \multicolumn{2}{|c|}{ OLSAH } & Chi Square Test & P-Value \\
\hline$<40$ & 35 & $70.0 \%$ & $2.9 \%$ & 1 & \multirow{4}{*}{0.4286} & \multirow{4}{*}{1} \\
\hline unknown & 5 & $10.0 \%$ & $0.0 \%$ & 0 & & \\
\hline$>10000$ & 3 & $6.0 \%$ & $0.0 \%$ & 0 & & \\
\hline $40-10000$ & 7 & $14.0 \%$ & $0.0 \%$ & 0 & & \\
\hline $\begin{array}{l}\text { Viral Load - ART } \\
\text { (not started) }\end{array}$ & All Patients & $\%$ & \multicolumn{2}{|c|}{ OLSAH } & Chi Square Test & P-Value \\
\hline$<40$ & 1 & $5.9 \%$ & $0.0 \%$ & 0 & \multirow{4}{*}{1.1636} & \multirow{4}{*}{1} \\
\hline $40-10000$ & 1 & $5.9 \%$ & $0.0 \%$ & 0 & & \\
\hline$>10000$ & 0 & $0.0 \%$ & $0.0 \%$ & 0 & & \\
\hline unknown & 15 & $88.2 \%$ & $40.0 \%$ & 6 & & \\
\hline Viral Load - ART Type 1 & All Patients & $\%$ & \multicolumn{2}{|c|}{ OLSAH } & Chi Square Test & P-Value \\
\hline$<40$ & 120 & $35.2 \%$ & $1.7 \%$ & 2 & \multirow{4}{*}{12.9821} & \multirow{4}{*}{0.0042} \\
\hline $40-10000$ & 73 & $21.4 \%$ & $5.5 \%$ & 4 & & \\
\hline$>10000$ & 52 & $15.2 \%$ & $15.4 \%$ & 8 & & \\
\hline unknown & 96 & $28.2 \%$ & $5.2 \%$ & 5 & & \\
\hline
\end{tabular}


Citation: Moodley A, Wood NH (2015) HIV-Associated Oral Lesions in HIV-Seropositive Patients at an HIV-Treatment Clinic in South Africa. J AIDS Clin Res 6: 422. doi:10.4172/2155-6113.1000422

Page 8 of 11

\begin{tabular}{|c|c|c|c|c|c|c|}
\hline Viral Load - ART Type 2 & All Patients & $\%$ & \multicolumn{2}{|c|}{ OLSAH } & Chi Square Test & P-Value \\
\hline$<40$ & 6 & $35.3 \%$ & $0.0 \%$ & 0 & \multirow{4}{*}{7.5} & \multirow{4}{*}{0.1176} \\
\hline $40-10000$ & 6 & $35.3 \%$ & $0.0 \%$ & 0 & & \\
\hline$>10000$ & 3 & $17.6 \%$ & $0.0 \%$ & 0 & & \\
\hline unknown & 2 & $11.8 \%$ & $50.0 \%$ & 1 & & \\
\hline Viral Load - ART Salvage & All Patients & $\%$ & \multicolumn{2}{|c|}{ OLSAH } & Chi Square Test & P-Value \\
\hline$<40$ & 31 & $51.7 \%$ & $3.2 \%$ & 1 & \multirow{4}{*}{10.8687} & \multirow{4}{*}{0.0143} \\
\hline $40-10000$ & 11 & $18.3 \%$ & $0.0 \%$ & 0 & & \\
\hline$>10000$ & 16 & $26.7 \%$ & $31.3 \%$ & 5 & & \\
\hline unknown & 2 & $3.3 \%$ & $0.0 \%$ & 0 & & \\
\hline Viral Load - Neutrophil count $(<2)$ & All Patients & $\%$ & \multicolumn{2}{|c|}{ OLSAH } & Chi Square Test & P-Value \\
\hline$<40$ & 45 & $28.1 \%$ & $0.0 \%$ & 0 & \multirow{4}{*}{6.9433} & \multirow{4}{*}{0.063} \\
\hline $40-10000$ & 40 & $25.0 \%$ & $7.5 \%$ & 3 & & \\
\hline$>10000$ & 33 & $20.6 \%$ & $15.2 \%$ & 5 & & \\
\hline unknown & 42 & $26.3 \%$ & $11.9 \%$ & 5 & & \\
\hline Viral Load - Neutrophil count $(\geq 2)$ & All Patients & $\%$ & \multicolumn{2}{|c|}{ OLSAH } & Chi Square Test & P-Value \\
\hline$<40$ & 100 & $46.1 \%$ & $3.0 \%$ & 3 & \multirow{4}{*}{11.4183} & \multirow{4}{*}{0.0087} \\
\hline $40-10000$ & 40 & $18.4 \%$ & $2.5 \%$ & 1 & & \\
\hline$>10000$ & 32 & $14.7 \%$ & $18.8 \%$ & 6 & & \\
\hline unknown & 45 & $20.7 \%$ & $8.9 \%$ & 4 & & \\
\hline Neutrophil Count - Age(20 - 30) & All Patients & Percentage & \multicolumn{2}{|c|}{ OLSAH } & Chi Square Test & P-Value \\
\hline$<2$ & 26 & $32.1 \%$ & $3.8 \%$ & 1 & \multirow{3}{*}{0.5982} & \multirow{3}{*}{0.7415} \\
\hline$\geq 2$ & 48 & $59.3 \%$ & $6.3 \%$ & 3 & & \\
\hline unknown & 7 & $8.6 \%$ & $0.0 \%$ & - & & \\
\hline Neutrophil Count - Age(31 - 40) & All Patients & $\%$ & \multicolumn{2}{|c|}{ OLSAH } & Chi Square Test & P-Value \\
\hline$<2$ & 66 & $36.1 \%$ & $6.1 \%$ & 4 & \multirow{3}{*}{1.783} & \multirow{3}{*}{0.4375} \\
\hline$\geq 2$ & 89 & $48.6 \%$ & $7.9 \%$ & 7 & & \\
\hline unknown & 28 & $15.3 \%$ & $14.3 \%$ & 4 & & \\
\hline Neutrophil Count - Age(41 - 50) & All Patients & $\%$ & \multicolumn{2}{|c|}{ OLSAH } & Chi Square Test & P-Value \\
\hline$<2$ & 47 & $39.5 \%$ & $10.6 \%$ & 5 & \multirow{3}{*}{2.2398} & \multirow{3}{*}{0.3828} \\
\hline$\geq 2$ & 61 & $51.3 \%$ & $4.9 \%$ & 3 & & \\
\hline unknown & 11 & $9.2 \%$ & $0.0 \%$ & - & & \\
\hline Neutrophil Count - Age(51 - 60) & All Patients & $\%$ & \multicolumn{2}{|c|}{ OLSAH } & Chi Square Test & P-Value \\
\hline$<2$ & 19 & $41.3 \%$ & $15.8 \%$ & 3 & \multirow{3}{*}{0.899} & \\
\hline$\geq 2$ & 17 & $37.0 \%$ & $5.9 \%$ & 1 & & 0.8303 \\
\hline unknown & 10 & $21.7 \%$ & $10.0 \%$ & 1 & & \\
\hline Neutrophil Count - CD4(<200) & All Patients & $\%$ & & & Chi Square Test & P-Value \\
\hline$<2$ & 76 & $42.9 \%$ & $11.8 \%$ & 9 & & \\
\hline$\geq 2$ & 80 & $45.2 \%$ & $12.5 \%$ & 10 & 0.7827 & 0.6982 \\
\hline unknown & 21 & $11.9 \%$ & $19.0 \%$ & 4 & & \\
\hline Neutrophil Count - CD4(200 - 500) & All Patients & $\%$ & & & Chi Square Test & P-Value \\
\hline$<2$ & 74 & $41.8 \%$ & $4.1 \%$ & 3 & & \\
\hline$\geq 2$ & 89 & $50.3 \%$ & $3.4 \%$ & 3 & 0.5877 & 1 \\
\hline unknown & 14 & $7.9 \%$ & $0.0 \%$ & - & & \\
\hline Neutrophil Count - CD4(> 500) & All Patients & $\%$ & & & Chi Square Test & P-Value \\
\hline
\end{tabular}




\begin{tabular}{|c|c|c|c|c|c|c|}
\hline$<2$ & 4 & $8.0 \%$ & $0.0 \%$ & - & \multirow{3}{*}{0.2195} & \multirow{3}{*}{1} \\
\hline$\geq 2$ & 41 & $82.0 \%$ & $2.4 \%$ & 1 & & \\
\hline unknown & 5 & $10.0 \%$ & $0.0 \%$ & - & & \\
\hline $\begin{array}{l}\text { CD4 count - No. of years diagnosed } \\
\text { with HIV (0-7) }\end{array}$ & All Patients & $\%$ & \multicolumn{2}{|c|}{ OLSAH } & Chi Square Test & P-Value \\
\hline $200-500$ & 149 & $38.6 \%$ & $2.7 \%$ & 4 & \multirow{4}{*}{11.2656} & \multirow{4}{*}{0.0121} \\
\hline$<200$ & 165 & $42.7 \%$ & $11.5 \%$ & 19 & & \\
\hline$>500$ & 44 & $11.4 \%$ & $2.3 \%$ & 1 & & \\
\hline unknown & 28 & $7.3 \%$ & $7.1 \%$ & 2 & & \\
\hline $\begin{array}{l}\text { CD4 count - No. of years diagnosed } \\
\text { with HIV (8-13) }\end{array}$ & All Patients & $\%$ & \multicolumn{2}{|c|}{ OLSAH } & Chi Square Test & P-Value \\
\hline $200-500$ & 20 & $54.1 \%$ & $10.0 \%$ & 2 & \multirow{4}{*}{3.5325} & \multirow{4}{*}{0.3909} \\
\hline$<200$ & 10 & $27.0 \%$ & $30.0 \%$ & 3 & & \\
\hline$>500$ & 5 & $13.5 \%$ & $0.0 \%$ & 0 & & \\
\hline unknown & 2 & $5.4 \%$ & $0.0 \%$ & 0 & & \\
\hline $\begin{array}{l}\text { CD4 count - No. of years diagnosed } \\
\text { with HIV }(>14)\end{array}$ & All Patients & $\%$ & \multicolumn{2}{|c|}{ OLSAH } & Chi Square Test & P-Value \\
\hline $200-500$ & 7 & $70.0 \%$ & $0.0 \%$ & 0 & \multirow{4}{*}{9} & \multirow{4}{*}{0.3} \\
\hline$<200$ & 1 & $10.0 \%$ & $100.0 \%$ & 1 & & \\
\hline$>500$ & 1 & $10.0 \%$ & $0.0 \%$ & 0 & & \\
\hline unknown & 1 & $10.0 \%$ & $0.0 \%$ & 0 & & \\
\hline CD4 count - Gender(F) & All Patients & $\%$ & \multicolumn{2}{|c|}{ OLSAH } & Chi Square Test & P-Value \\
\hline $200-500$ & 128 & $43.1 \%$ & $1.6 \%$ & 2 & \multirow{4}{*}{17.0343} & \multirow{4}{*}{0.0014} \\
\hline$<200$ & 103 & $34.7 \%$ & $14.6 \%$ & 15 & & \\
\hline$>500$ & 44 & $14.8 \%$ & $2.3 \%$ & 1 & & \\
\hline unknown & 22 & $7.4 \%$ & $9.1 \%$ & 2 & & \\
\hline CD4 count - Gender(M) & All Patients & $\%$ & \multicolumn{2}{|c|}{ OLSAH } & Chi Square Test & P-Value \\
\hline $200-500$ & 47 & $35.1 \%$ & $8.5 \%$ & 4 & \multirow{4}{*}{1.8831} & \multirow{4}{*}{0.6001} \\
\hline$<200$ & 72 & $53.7 \%$ & $11.1 \%$ & 8 & & \\
\hline$>500$ & 6 & $4.5 \%$ & $0.0 \%$ & 0 & & \\
\hline unknown & 9 & $6.7 \%$ & $0.0 \%$ & 0 & & \\
\hline
\end{tabular}

Table 3: Multivariate analysis of individual parameters as predictors for the development of OLSAH.

4+ T-cell counts $<200$ cell $/ \mathrm{mm}^{3}$ specifically, and viral loads, showed significant correlation with predicting OLSAH. Assessment of viral load together with ART showed that specifically ART Type 1 and Salvage treatment had a significant predictive value for OLSAH, but ART type 2 did not show such a result. Viral load and neutrophil counts $\geq 2$ also proved to be a significant predictive factor for OLSAH (Table 3 ).

The CD 4+ T-cell count and the period since diagnosis, specifically between 0-7 years, were also significant in predicting the prevalence of OLSAH. CD 4+ T-cell count and the patients sex were also assessed and when looking at these variables together, the female participants showed a significant predictive value (Table 3 ).

\section{Conclusion}

Results of this study demonstrated that the CD4+ T cell count, viral load and the efficiency of antiretroviral treatment were all significant factors in determining the prevalence of OLSAH at this clinic. This information can assist healthcare workers in HIV clinics gauge the immune status of an HIV-seropositive individual as those who present with OLSAH probably have high viral loads and low CD4+ T cell counts. HAART failure or success is determined by monitoring viral loads and CD4+ T cell count and implies that the presence OLSAH can serve as an indicator of HAART failure. This can be very beneficial in resource poor settings, were viral load monitoring is not always possible. Therefore the presence of OLSAH should, at present, necessitate further investigation, appropriate referral and treatment modification.

Even though pseudomembranous candidiasis was the most prevalent lesion in this study, which correlates to other similar studies, oral hairy leukoplakia was seen at much lower rates in this study. This could also be attributed to the fact that higher rates of our participants were also on HAART.

Our study did not correlate with the higher prevalence of OLSAH as seen in other similar studies (Appendix 3), where prevalence rates ranged from $15 \%-86.6 \%$. In the study with the highest prevalence rate [19], some patients were on HAAR T whilst others were HAARTnaive. However, the percentage of patients that were HAART- naïve, were much higher when compared to this study, as $89.3 \%$ of patients were HAART naive. In this study $96 \%$ of study participants were on HAART. This could account for the discrepancy seen in the prevalence of OLSAH, as patients on HAART are known to present with a lower prevalence rate OLSAH.

Currently, protocols that are in place for monitoring HIV- 
Citation: Moodley A, Wood NH (2015) HIV-Associated Oral Lesions in HIV-Seropositive Patients at an HIV-Treatment Clinic in South Africa. J AIDS Clin Res 6: 422. doi:10.4172/2155-6113.1000422

seropositive patients on HAART, even in resource poor settings, remain the standard of practice. The occurrence of oral lesions in patients on HAART should also make healthcare workers aware that patients on HAART may still be at risk of developing opportunistic infections, especially those patients who have just started HAART, in those on salvage treatments and in those who have defaulted on their treatment.

\section{References}

1. Leão JC, Ribeiro CMB, Carvalho AAT, Frezzini C, Porter S (2009) Review: Oral Complications of HIV Disease. Clinics 64: 459-470.

2. Global report (2011) UNAIDS report on the global AIDS epidemic 2010. WHO Publications.

3. Bhayat A, Yengopal V, Rudolph M (2010) Predictive value of group I oral lesions for HIV infection. Oral Surg Oral Med Oral Pathol Oral Radiol Endod 109: 720 723.

4. Tirwomwe JF, Rwenyonyi CM, Muwazi LM, Besigye B, Mboli F (2007) Oral manifestations of HIVIAIDS in clients attending TASO clinics in Uganda. Clin Oral Invest 11: 289-292.

5. Mataftsi M, Skoura L, Sakellari D (2011) HIV infection and periodontal diseases: an overview of the post-HAART era. Oral Dis 17: 13-25

6. Jha R, Kaur T, Sharma A (2014) Oral manifestations of HIV-AIDS: a diagnostic and management dilemma. J Res Med Dent Sci 2: 96-101.

7. Arendorf TM, Bredekamp B, Cloete CAC, Sauer G (1998) Oral manifestations of HIV infection in 600 South African patients. J Oral Pathol Med 27: 176-179.

8. Naidoo S, Chikte U (2004) Oro-facial manifestations in paediatric HIV: a comparative study of institutionalized and hospital outpatients. Oral Diseases 10: 13-18.

9. Blignaut E (2007) Oral candidiasis and oral yeast carriage among institutionalised South African paediatric HIVIAIDS patients. Mycopathologia 163: 67-73.

10. Yengopal V, Naidoo S (2008) Do oral lesions associated with HIV affect quality of life? Oral Surg Oral Med Oral Pathol Oral Radiol Endod 106: 66-73.

11. Kamiru HN, Naidoo S (2002) Oral HIV lesions and oral health behaviour of HIVpositive patients attending the Queen Elizabeth II Hospital, Maseru, Lesotho. SADJ 57: 479-482.

12. Chidzonga MM (2003) HIVIAIDSorofacial lesions in 156 Zimbabwean patients at referral oral and maxillofacial surgical clinics. Oral Dis 9: 317-322.

13. Duggal MS, Abudiak H, Dunn C, Tong HJ, Munyombwe T (2010) Effect of CD4+ lymphocyte count, viral load, and duration of taking anti-retroviral treatment on presence of oral lesions in a sample of South African children with HIVIAIDS. Eur Arch Paed Dent 11: 242-246.

14. Mthethwa SR, Wanjau J, Chabikuli N (2013) The prevalence of HIV associated oral lesions among adults in the era of HAART. SADJ 8: 364-371.

15. Hamza OJM, Matee MIN, Simon ENM, Kikwilu E, Moshi MJ, et al. (2006) Oral manifestations of HIV infection in children and adults receiving highly-active antiretroviral therapy [HAART] in Dar es Salaam, Tanzania. BMC Oral Health 6: 12.

16. Shiboski CH, Patton LL, Webster- Cyriaque JY, Greenspan D, Traboulsi RS et al. (2009) The Oral HIVIAIDS Research Alliance; Subcommittee of the AIDS Clinical Trial Group. J Oral Pathol Med 38: 481-488.

17. Classification and Diagnostic criteria for oral lesions in HIV infection (1993) EC Clearinghouse on Oral Problems related to HIV infection and WHO Collaborating Centre on Oral Manifestations of the Immunodeficiency Virus. J Oral Pathol Med 22: 289-291.

18. National Department of Health (2004) National Antiretroviral Treatment Guideline.

19. Ranganathan K, Umadevi M, Saraswathi TR, Kumarasamy N, Solomon S, et al (2004) Oral Lesions and Conditions Associated with Human Immunodeficiency Virus Infection in 1000 South Indian Patients. Ann Acad Med Singapore 33 (Suppl): 37S- 42S

20. Adedigba MA, Ogunbodede EO, Jeboda SO, Naidoo S (2008) Patterns of oral manifestation of HIVIAIDS among 225 Nigerians patients. Oral diseases 14 341-346.
21. Gaurav S, Keerthilatha MP, Nagpal A (2011) Prevalence of oral manifestations and their associaion with CD4/CD8 Ratio and HIV Viral Load in South India Int J Dent.

22. Anil S, Challacombe SJ (1997) Oral lesions of HIV and AIDS in Asia: an overview. Oral Diseases 3(Suppl 1): S36-S40.

23. Ceballos-Salobreña A, Gaitan-Cepeda LA, Ceballos-Garcia L, Lezama-De Valle D (2000) Oral Lesions in HIVIAIDS Patients Undergoing Highly Active Anti-retroviral Treatment Including Protease Inhibitors: A New Face of Oral AIDS? AIDS Patient Care STDs 14: 627-635.

24. Sen S, Mandal S, Bhattacharya S, Halder S, Bhaumik P (2010) Ora Manifestations in Human Immunodeficiency Virus Infected Patients. Indian $J$ Dermatol 55: 116-118.

25. Flint SR, Tappuni A, Leigh J, Schmidt-Westhausen AM, MacPhail L (2006) (B3) Markers of Immunodeficiency and Mechanisms of HAART Therapy on Oral Lesions. Adv Dent Res 19: 146-151.

26. Ramirez-Amador V, Esquivel- Pedraza L, Sierra-Madero J, Anaya-Saavedra G Gonzalez- Ramirez I, et al. (2003) The Changing Clinical Spectrum of Human Immunodeficiency Virus (HIV)- Related Oral Lesions in 1,000 Consecutive Patients A 12- Year Study in a Referral Centre in Mexico. Medicine 82: 39-50.

27. Taiwo OO, Hassan Z (2010) The impact of Highly Active Antiretroviral Therapy (HAART) on the clinical features of HIV- related oral lesions in Nigeria. AIDS Research and Therapy 7: 19

28. Patton LL (2000) Sensitivity, specificity, and positive predictive value of ora opportunistic infections in adults with HIVIAIDS as markers of immune suppression and viral burden. Oral Surg Oral Med Oral Pathol Oral Radiol Endod 90: 182-188.

29. Ranganathan K, Hemalatha R (2006) Oral Lesions in HIV Infection in Developing Countries: an Overview. Adv Dent Res 19: 63-68.

30. Masiiwa A, Naidoo S (2011) Oral lesions in HIV-infected patients, before and after antiretroviral treatment. South Afr J Epidemiol Infect 26: 271-273.

31. Noce CW, Ferreira SM, Silva Junior A, Dias EP (2009) Association between socioeconomic status and HIV- associated oral lesions in Rio de Janeiro from 1997 to 2004. Braz Oral Res 23: 149-54.

32. Shangase L, Feller L,Blignaut E (2004) Necrotising ulcerative ginigivitis/ Periodontitis as indicators of HIV infection. SADJ 59: 105-108.

33. Wood NH, Blignaut E, Lemmer J, Meyerov R, Feller L (2011) Necrotizing periodontal diseases in a semi-rural district of South Africa. AIDS Res Treat 2011.

34. Baccaglini L, Atkinson JC, Patton LL, Glick M, Ficarra G, et al. (2007) Management of oral lesions in HIV- positive patients. Oral Surg Oral Med Oral Pathol Oral Radiol Endo 103 (suppl 1): S50.e1-S50.e23.

35. Coogan MM, Greenspan J, Challacombe SJ (2005) Oral lesions in infection with human immunodeficiency virus. Bulletin of the World Health Organization 83: 700-706

36. Bajomo AS, Ayo-Yusuf OA, Rudolph MJ, Tsotsi NM (2013) Impact of ora lesions among South African adults with HIVIAIDS on oral health-related quality of life. J Dent Sci 8: 412-417.

37. Lourenço AG, Motta ACF, de Figueiredo LTM, Machado AA, Komesu MC (2011) Oral lesions associated with HIV infection before and during the antiretroviral therapy era in Ribeirao Preto, Brazil. J Oral Sci 53: 379-385.

38. Bodhade AS, Ganvir SM, Hazarey VK (2011) Oral manifestations of HIV infection and their correlation with CD4 count. J Oral Sci 53: 203-211.

39. Bhayat A, Yengopal V, Rudolph MJ, Nemutandani MS (2008) Predicting HIV in a Public Dental Facility Using Group I Oral Lesions. SADJ 63: 538-543.

40. Ortega K, Ceballos-Salobreña A, Gaitán-Cepeda LA, Magalhães MG (2008) Oral manifestation after immune reconstitution in HIV patients on HAART. International Journal of STD and AIDS 19: 305-308.

41. Ortega KL, Vale DA, Malgalhães MH (2009) Impact of PI and NNRTI HAARTbased therapy on oral lesions of Brazilian HIV- infected patients. J Oral Pathol Med 38: 489-494.

42. Gaurav S, Keerthilatha MP, Setty S, Ramapuram JT, Nagpal A (2009) Oral manifestations as predictors of immune suppressions in HIV-IAIDS- infected population in south India. Clin Oral Inves 13: 141-148. 
Citation: Moodley A, Wood NH (2015) HIV-Associated Oral Lesions in HIV-Seropositive Patients at an HIV-Treatment Clinic in South Africa. J AIDS Clin Res 6: 422. doi:10.4172/2155-6113.1000422

43. Carpio E, Lopez V, Fardales V, Benitez I (2009) Oral manifestations of HIV infection in adult patients from the province of Sancti Spiritus, Cuba. J Oral Pathol Med 38:126-131.

44. Khatibi M, Moshari AA, Jahromi ZM, Ramezankhani A (2011) Prevalence of oral mucosal lesions and related factors in $200 \mathrm{HIV+/AIDS} \mathrm{Iranian} \mathrm{patients.} \mathrm{J} \mathrm{Oral}$ Pathol Med 40: 659-664.

45. Lourenço AG, Figueiredo LTM (2008) Oral lesions in HIV infected individuals from Ribeirão Preto, Brazil. Med Oral Patol Oral Cir Bucal 13: E281-286.
46. Palacio H, Hilton JF, Canchola AJ, Greenspan D (1997) Effect of Cigarette Smoking on HIV- Related Oral Lesions. J Acq Immune Defic Syndr Hum Retrovirol14: 338-342.

47. Nittayananta W, Chanowanna N, Sripatanakul S, Winn T (2001) Risk Factors associated with oral lesions in HIV infected heterosexual people and intravenous drug users in Thailand. J Oral Pathol Med 30: 224-230.

48. Rooban T, Rao A, Joshua E, Ranganathan K (2009)The prevalence of oral mucosal lesions in alcohol misusers in Chennai, South India. Indian Journal of Dental Research 20: 41-46. 